\title{
The inflation and inflation uncertainty relationship for Turkey: a dynamic framework
}

\author{
M. Hakan Berument • Yeliz Yalcin • \\ Julide O. Yildirim
}

Received: 20 June 2008 / Accepted: 5 March 2010 / Published online: 15 June 2010

(C) Springer-Verlag 2010

\begin{abstract}
This article assesses the interaction between inflation and inflation uncertainty in a dynamic framework for Turkey by using monthly data for the time period 1984-2009. The bulk of previous studies investigating the link between inflation and inflation uncertainty employ Autoregressive Conditional Heteroskedasticity (ARCH)type models, which consider inflation uncertainty as a predetermined function of innovations to inflation specification. The stochastic volatility in mean (SVM) models that we use allow for gathering innovations to inflation uncertainty and assess the effect of inflation volatility shocks on inflation over time. When we assess the interaction between inflation and its volatility, the empirical findings indicate that response of inflation to inflation volatility is positive and statistically significant. However, the response of inflation volatility to inflation is negative but not statistically significant.
\end{abstract}

Keywords Inflation - Inflation uncertainty - Stochastic volatility models · VAR · Impulse response

JEL Classification C15 - C22 - E31

\footnotetext{
M. H. Berument $(\varangle)$

Department of Economics, Bilkent University, 06800 Ankara, Turkey

e-mail: berument@bilkent.edu.tr

URL: http://www.bilkent.edu.tr/ berument/

Y. Yalcin · J. O. Yildirim

Department of Econometrics, Gazi University, 06500 Ankara, Turkey

e-mail: yyeliz@gazi.edu.tr

URL: http://yyelizyalcin.googlepages.com/

J. O. Yildirim

e-mail: julide@gazi.edu.tr
} 


\section{Introduction}

Even though the positive relationship between inflation and inflation variability is a well-established phenomenon, there is no consensus in the literature about the direction the relationship between inflation and inflation uncertainty takes. One strand of the literature claims that inflation uncertainty is likely to be high during periods of high inflation (Friedman 1977) — inflation leads to inflation uncertainty. Ball (1992) supports Friedman's hypothesis, arguing that there is greater uncertainty about future monetary policy during periods of high inflation. Ball (1992), Brunner and Hess (1993) and Grier and Perry $(1998,2000)$ provide empirical evidence suggesting a positive association between inflation and its variance. However, another strand of the literature argues that higher inflation uncertainty leads to a rise in the optimal inflation rate (Cukierman and Meltzer 1986; Cukierman 1992) with empirical evidence provided by Grier and Perry (1998) and Berument et al. (2005). Holland (1993, 1995) suggests that inflation uncertainty may lower the average inflation rate, provided that the central bank tries to minimize welfare losses arising from more inflation uncertainty.

Empirical evidence regarding the relationship between inflation and inflation uncertainty for Turkey is provided by a number of studies that employ alternative estimation methods, i.e. different measures of inflation and for different time periods. Nas and Perry (2000) investigate the link between inflation and inflation uncertainty using the Granger causality test by constructing a time series of monthly inflation uncertainty in Turkey for the period 1960-1998, employing Generalized Autoregressive Conditional Heteroskedasticity $(\mathrm{GARCH})$ models. Their empirical findings indicate that increased inflation significantly increases inflation uncertainty, while increased inflation uncertainty is associated with lower average inflation. Neyapti (2000) tests the association between the level of inflation and its uncertainty in Turkey between 1982 and 1999 using the monthly Wholesale Price Index. She reports that there is a positive and significant relationship between the two variables. Berument et al. (2001) model inflation uncertainty in Turkey using the Exponential General Autoregressive Conditional Heteroskedastic (EGARCH) method for the period 1986-2000 using monthly CPI inflation. Their empirical findings indicate that the effect of positive shocks to inflation on inflation uncertainty is greater than that of negative shocks to inflation. Telatar and Telatar (2003) investigate relationship between inflation and different sources of inflation uncertainty in Turkey during the period 1995-2000 using monthly data in a framework of a time-varying parameter model of inflation with heteroskedastic disturbances. They report that inflation Granger causes inflation uncertainty. However, they do not find any evidence on the correlation between inflation and its uncertainty due to heteroskedasticity in the disturbance term. Ozer and Turkyilmaz (2005) examine the relationship between inflation and inflation uncertainty from 1990:04 to 2004:04 in Turkey using the EGARCH model and Granger causality, impulse response and variance decomposition analyses. They find that inflation causes inflation uncertainty.

The bulk of previous studies employ ARCH-type models for inflation uncertainty, including specifications such as ARCH, GARCH and EGARCH. In these specifications, inflation uncertainty (here, called conditional variance) is predetermined at a given time; the inflation uncertainty measure is a function of the lag values of conditional variances and/or lagged residuals of inflation specifications. Thus, the model 
specification does not show how an unanticipated change in the uncertainty measure affects inflation, but does allow us to assess how a predetermined uncertainty measure moves with inflation. However, Stochastic Volatility (SV) models allow for shocks in the volatility that may lead us to assess the dynamic effects of volatility shocks on other economic variables. This way of modelling enables the researcher to assess how innovation in inflation uncertainty will affect inflation itself in a dynamic framework. Assessing this dynamic effect is important because the long-term and short-term prospects of inflation uncertainty may affect inflation differently (Klein 1978; Evans 1991). Moreover, even if ARCH-type models cannot be directly comparable with SV models because they non-nest each other (for example, Franses et al. 2008), various studies provide empirical evidence that SV models provide a better fit compared to ARCH models (for example, Danielsson 1994; Kim et al. 1998). Thus, we employ SV in our specifications.

The purpose of this study is to investigate the dynamic link between inflation and inflation uncertainty for Turkey from 1984 to 2009 using monthly data. In order to capture the dynamics, impulse responses are gathered by using this SV model, which allows for a stochastic element in the time-series evolution of the conditional variance process. The type of the models that are employed to assess the relationship between inflation and inflation uncertainty are univariate in general. In these models, inflation shock is defined as the surprise in the realization of contemporaneous inflation relative to what would have been predicted based on past realizations. It is quite likely, however, that the contemporaneous inflation shock from such a univariate autoregression also includes contemporaneous shocks to other sets of variables such as interest rates and output that are not controlled for in a univariate setup. In this sense, the 'inflation shock' from the univariate model is not well identified and the reader should be cautious about the interpretation. This article proceeds as follows: Sect. 2 presents the modelling approach. In Sect. 3, the data set is defined and estimation results are discussed, and conclusions are given in Sect. 4.

\section{Model}

In order to capture the dynamics of inflation, we adopt the Stochastic Volatility in Mean model (SVM) proposed by Koopman and Uspensky (2002). The mean equation for the SVM model is

$$
\pi_{t}=a+\sum_{i=1}^{k} b_{i} x_{i, t}+d \sigma_{t}^{2}+\sigma_{t} \varepsilon_{t}, \quad \varepsilon_{t} \sim N I D(0,1)
$$

where $\pi_{t}$ represents inflation and depends on a set of explanatory variables $x_{i, t}, i=$ $1, \ldots, k$, which may also contain the lagged values of endogenous variable and an inflation volatility measure $\sigma_{t}^{2}, d$ is an inflation volatility premium coefficient to capture the volatility-in-mean effect and $a, b_{1}, \ldots, b_{k}$ are the other parameters of interest. 
The variance equation ${ }^{1}$ for SVM is specified in logarithmic form,

$$
\sigma_{t}=\sigma^{*} \exp \left(0.5 h_{t}\right)
$$

where $\sigma^{*}$ is a positive scaling factor. This equation, as a first-order autoregressive model of the stochastic process $h_{t}=\ln \left(\sigma_{t}^{2} / \sigma^{* 2}\right)$, is written as

$$
h_{t}=\phi h_{t-1}+\sigma_{\eta} \eta_{t}, \quad \eta_{t} \sim N I D(0,1)
$$

The lagged values of the exogenous variables ${ }^{2}$ and the dependent variable can also be included to variance specification at time $t .{ }^{3}$ The variance of the log-volatility process, $\sigma_{\eta}^{2}$, measures the uncertainty about future volatility. The SVM model is represented by Eqs. 1 and 2, and it is assumed that the disturbances $\varepsilon_{t}$ and $\eta_{t}$ are mutually uncorrelated contemporaneously and at all lags. If $d$ - the volatility-in-mean effect-is zero or is not statistically significant, the SVM model will turn into the SV model. In our model, the mean equation of inflation is an Autoregressive (AR) process, which is similar to Grier and Perry (2000) and Berument et al. (2005) in capturing the dynamics of the inflation process. Importantly, in this study we extend this model as a $p$ th order of the SVM model and add lag variables of the volatility-in-mean effect in the mean equation, which can be represented as follows:

1 ARCH- type models define the time-varying variance as a predetermined function of past squared innovations. The $\mathrm{ARCH}(\mathrm{q})$ model can be written as

$$
\sigma_{t}^{2}=\alpha_{0}+\sum_{i=1}^{q} \alpha_{i} \varepsilon_{t-i}^{2}
$$

the $\operatorname{GARCH}(\mathrm{p}, \mathrm{q})$ model can be written as

$$
\sigma_{t}^{2}=\alpha_{0}+\sum_{i=1}^{q} \alpha_{i} \varepsilon_{t-i}^{2}+\sum_{i=1}^{p} \beta_{i} \sigma_{t-i}^{2} \text { and }
$$

The EGARCH(p,q) model can be written as

$$
\ln \sigma_{t}^{2}=\gamma+\sum_{i=1}^{p} \beta_{i} \ln \sigma_{t-i}^{2}+\sum_{i=1}^{q} \alpha_{i}\left(\left|\varepsilon_{t-i} / \sigma_{t-i}\right|-E\left|\varepsilon_{t-i} / \sigma_{t-i}\right|-L\left(\varepsilon_{t-i} / \sigma_{t-i}\right)\right),
$$

where $\sigma_{t}^{2}$ is the conditional variance of $\varepsilon_{t}$ and $\ln \sigma_{t}^{2}$ is denoted as $h_{t}$ in the SVM specification that we use in the article. ARCH models only include lag (pre-determined) squared residuals of the inflation equation $\left(\varepsilon_{t-i}^{2}\right)$. GARCH models also include past conditional variances, $\sigma_{t-i}^{2}$, along with past squared innovations, $\varepsilon_{t-i}^{2}$. Similarly, EGARCH models include the logarithm of past conditional variances

2 Since including explanatory variables at time $t$ could give a biased estimator for $\ln \sigma_{t}^{2}$, we do not allow the variance equation to include any variable at time $t$. Moreover, as the term $\ln \sigma^{* 2}$ can be regarded as the constant term in the logarithm of the volatility equation $\left(h_{t}\right)$, the logarithm of the volatility process does not include an additional intercept term (Hol and Koopman 2000).

3 A full discussion of the SVMs and their estimation procedures are provided in the appendix. 


$$
\pi_{t}=a+\sum_{i=1}^{k} b_{i} \pi_{t-i}+\sum_{i=0}^{m} d_{i} \sigma^{* 2} \exp \left(h_{t-i}\right)+\sigma^{*} \exp \left(0.5 h_{t}\right) \varepsilon_{t}, \quad \varepsilon_{t} \sim N I D(0,1)
$$

$$
h_{t}=\sum_{i=1}^{p} \phi_{i} h_{t-i}+\sum_{i=1}^{n} \delta_{i} \pi_{t-i}+\sigma_{\eta} \eta_{t}, \quad \eta_{t} \sim N I D(0,1)
$$

The parameters of this model are estimated by exact maximum likelihood methods, using Monte Carlo importance sampling techniques and using programs written in Doornik (1998) Ox language, using SsfPack by Koopman et al. (1999). ${ }^{4}$

\section{Empirical results}

In this study, seasonally adjusted monthly data from the Turkish Consumer Price Index (CPI) covering the period from 1984:01 to 2009:02 is used. ${ }^{5}$ These data were collected from the electronic data delivery system of the Central Bank of the Republic of Turkey. ${ }^{6}$ Inflation is measured by the monthly difference of the logarithm of the price level. This series, later, is seasonally adjusted with the Tramo/Seats method. The time period covers the 1994 April financial crisis, so we use a dummy variable in the SVM model in order to capture any possible outlier that might be due to the crisis. The SVM model defined in Eq. 3a, b is estimated jointly using this series. For the determination of the optimal lag lengths of the model, the Akaike Information Criteria (AIC) has been employed. ${ }^{7}$ Table 1 reports the SVM-model estimation results. The parameters of the mean equation estimation results are presented in the first part of Table 1, together with their $95 \%$ confidence intervals. On the other hand, the estimates of the variance equation parameters are reported in the second part. Empirical results indicate that except for the parameter of $\pi_{t-1}$, all parameter estimates in the variance equation are statistically significant because their confidence bands do not include zero. Moreover, volatility persistence estimates are statistically significant and their sum is less than one in an absolute value, indicating that the volatility process is stationary.

Even though the coefficient of $\pi_{t-1}$ in a variance equation is not statistically significant, it is included as suggested by the AIC; this allows for examining the effects

\footnotetext{
4 The package is downloadable from http://sites.google.com/site/yyelizyalcin/koopman-et-al-1999-scodes.

5 The Turkish monthly data are only available after 1968. Turkey did not have a serious inflation problem nor did it consider inflation an important issue before 1976. We could have started the sample in 1976, however, Turkey had a military government between 1980 and 1983, and during this period, the government was attempting to control inflation with price freezes; we did not want to include this market unfriendly period in our analyses. The first elected democratic government was established on 13 December, 1983, and thus we start our sample in 1984.

6 http://www.tcmb.gov.tr.

7 As a part of robustness of the estimates, we also consider alternative lag lengths. However, the AIC suggests the lag length of two.
} 
Table 1 Estimation results for the SV model (1984:01-2009:02)

\begin{tabular}{llllll}
\hline & Constant & $\pi_{t-1}$ & $\pi_{t-2}$ & $\begin{array}{l}\text { Dummy } \\
(1994: 04 \text { and 1994:05 }\end{array}$ & \\
& & & $\begin{array}{l}\exp \left(0.5 h_{t}\right) \varepsilon_{t} \\
\text { are 1, others zero })\end{array}$ & \\
\hline$\pi_{t}$ & 0.1605 & 0.5788 & 0.3314 & 0.4922 & 0.7330 \\
& {$[0.0454: 0.2756]$} & {$[0.5052: 0.6745]$} & {$[0.2756: 0.6756]$} & {$[0.2337: 0.5462]$} & {$[0.6522: 0.8238]$} \\
\hline & $h_{t-1}$ & $h_{t-2}$ & $\pi_{t-1}$ & $\eta_{t}$ & \\
\hline$h_{t}$ & 0.4372 & 0.4113 & 0.0007 & 0.6987 & \\
& {$[0.2435: 0.6522]$} & {$[0.3283: 0.4996]$} & {$[-0.0261: 0.0739]$} & {$[0.3793: 1.2870]$} & \\
\hline
\end{tabular}

AIC: 985.723 Q(6): 0.1369 (0.7113) Q (12) : 7.9413 (0.004) Q (24) : 0.0015 (0.9685)

Normality Test Statistics of the standardized residuals $4.226(0.1208)$

Note: Numbers in parentheses and brackets are the $p$ values and confidence intervals at $95 \%$, respectively. $Q(i)$ reports Wooldridge (1991)'s robust LM test for $i$ th lag and $p$ values are reported next to test statistics in parentheses.

of inflation on inflation uncertainty. The estimate suggests that inflation has a positive impact on inflation variability, but this impact is not significant. This result is parallel to the implications of the Friedman (1977) and Ball (1992) models, and to the empirical evidence provided by Berument et al. (2005). With regard to the distributional assumptions for the standardized error term $\left(\varepsilon_{t}\right)$, the presence of autocorrelation of the standardized residual is tested by using the Lagrangian Multiplier (LM) test, suggested by Wooldridge (1991), for 6, 12 and 24 periods. The hypothesis that the first 6 and 24 autocorrelation coefficients of $\varepsilon_{t}$ are equal to zero cannot be rejected at the 5\% significance level. Since the Jarque-Berra Normality test statistic is smaller than the critical value $\chi_{2}^{2}$ at $5 \%$ significance, then the null hypothesis of normally distributed disturbances cannot be rejected. Therefore, the normality test statistic indicates that standardized error term has a normal distribution.

In order to study the dynamic relationships between inflation and inflation volatility, we have employed impulse response analyses. Writing impulse responses explicitly for non-linear models for general specifications is not possible (van Dijk et al. 2007). In order to calculate impulse responses, we used the stochastic simulation method, as suggested by Koop et al. (1996), around its initial values, as suggested by Yao and Tong (1994).

The impulse-response function generally traces the responses of $\pi_{t+k}$ and $h_{t+k}$ to primitive exogenous shocks $\varepsilon_{t}$ and $\eta_{t} \mathrm{k}=0,1,2 \ldots$. However, Hamilton (1994) argues that a more technically sound interpretation of an empirical impulse-response function is the revision in the conditional forecast of a variable given primitive shocks. In this article, we will calculate $\partial E\left(\pi_{t+k} \mid \varepsilon, \eta, \Omega_{t-1}\right) / \partial \varepsilon_{t}, \partial E\left(\pi_{t+k} \mid \varepsilon, \eta, \Omega_{t-1}\right) / \partial \eta_{t}, \partial E$ $\left(h_{t+k} \mid \varepsilon, \eta, \Omega_{t-1}\right) / \partial \varepsilon_{t}$ and $\partial E\left(h_{t+k} \mid \varepsilon, \eta, \Omega_{t-1}\right) / \partial \eta_{t}$, where $\varepsilon_{t}$ and $\eta_{t}$ are given shocks and $\Omega_{t-1}$ denotes the available information set at time $t-1$ for impulse responses (Elder 2004). These shocks also affect $\pi_{t}$ and $h_{t}$, not only through mean 

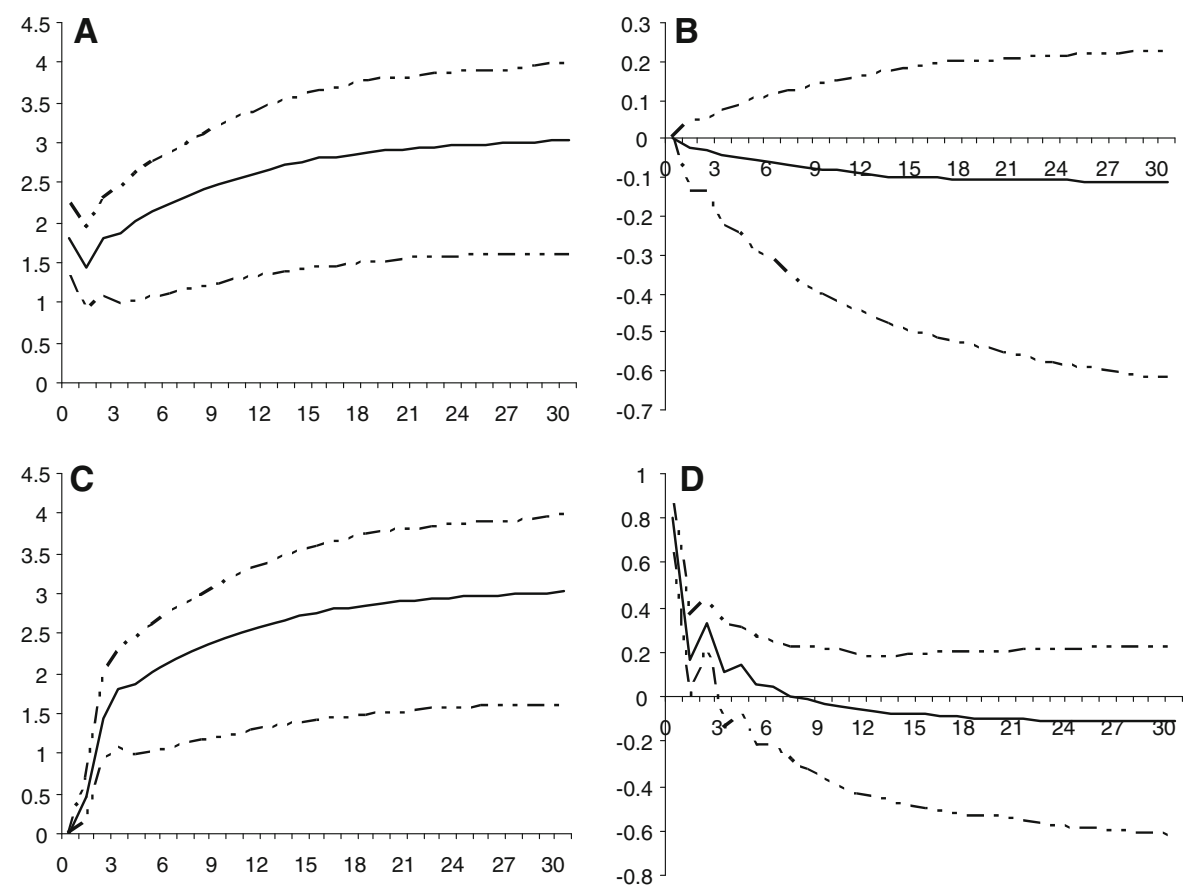

Fig. 1 The impulse responses of inflation and inflation volatility: 1984:01-2009:02. a Response of inflation to inflation, $\mathbf{b}$ Response of inflation volatility to inflation, $\mathbf{c}$ Response of inflation to inflation volatility d Response of inflation volatility to inflation volatility

but also with variance in the SVM model. Therefore, deriving an impulse-response function for our model is more complicated than that for traditional VARs.

Note that ARCH-type models take $\eta_{t}=0$ for all $t$. Thus, it is not plausible to introduce a shock to inflation volatility and assess the effect of inflation to inflation. In order to capture the instantaneous and dynamic effects of inflation and inflation variability, we examined impulse responses obtained from our specifications. When a unit shock is given for $\varepsilon_{t}$ and $\eta_{t}$, the impulse responses of inflation and inflation volatility are calculated. In order to make statistical inferences for the impulse response analysis, the $95 \%$ confidence intervals based on the bootstrap simulation with 250 trials are calculated. Impulse responses and confidence bands for 1984-2009 are plotted in Fig. 1, where the impulse responses are for 30 periods.

Note that parallel to Koopman and Uspensky (2002), $\operatorname{Cov}\left(\eta_{t}, \varepsilon_{t}\right)$ was taken as zero. Thus, there is neither the contemporaneous effect of inflation shock to inflation variability nor the contemporaneous effect of inflation volatility shock to inflation. Figure 1 suggests that the response of inflation to an inflation shock and the response of inflation to an inflation volatility shock seem permanent. These effects are statistically significant for the 30 periods that we consider. The response of inflation volatility to an inflation shock is negative but this effect is not statistically significant. However, the response of inflation volatility to an inflation volatility shock is short lived; 
Table 2 Estimation results for the SV model (1984:01-1993:12)

\begin{tabular}{lllll}
\hline & Constant & $\pi_{t-1}$ & $\pi_{t-2}$ & $\exp \left(0.5 h_{t}\right) \varepsilon_{t}$ \\
\hline$\pi_{t}$ & $\begin{array}{l}2.1829 \\
{[2.0036: 2.3622]}\end{array}$ & $\begin{array}{l}0.2816 \\
{[0.2685: 0.4326]}\end{array}$ & $\begin{array}{l}0.1331 \\
{[0.1195: 0.2493]}\end{array}$ & \begin{tabular}{l} 
[4.0712: 5.8255] \\
\hline
\end{tabular} \\
\hline$h_{t-1}$ & $h_{t-2}$ & $\pi_{t-1}$ & $\eta_{t}$ \\
\hline & 0.00065 & 0.3460 & 0.0029 & 0.5291 \\
\hline
\end{tabular}

AIC: 453.12 Q(6): 0.4140 (0.5199) Q (12) : 2.2017 (0.1378) Q (24) : 0.3028 (0.5820)

Normality Test Statistics of the standardized residuals 0.954 (0.6206)

Note: Numbers in parentheses and brackets are the $p$ values and confidence intervals at $95 \%$, respectively. $Q(i)$ reports Wooldridge (1991)'s robust LM test for $i$ th lag and $p$ values are reported next to test statistics in parentheses.

Table 3 Estimation results for the SV model (1995:01-2009:02)

\begin{tabular}{lllll}
\hline & Constant & $\pi_{t-1}$ & $\pi_{t-2}$ & $\exp \left(0.5 h_{t}\right) \varepsilon_{t}$ \\
\hline$\pi_{t}$ & 0.1469 & 0.6190 & 0.3100 & 0.3790 \\
& {$[-0.0033: 0.2972]$} & {$[0.3841: 0.6654]$} & {$[0.2453: 0.5382]$} & {$[0.3261: 0.4405]$} \\
\hline & $h_{t-1}$ & $h_{t-2}$ & $\pi_{t-1}$ & $\eta_{t}$ \\
\hline$h_{t}$ & 0.2555 & 0.4739 & -0.0270 & 0.9009 \\
& {$[0.0667: 0.6223]$} & {$[0.3841: 0.5654]$} & {$[-0.0852: 0.0311]$} & {$[0.4758: 1.7059]$} \\
\hline
\end{tabular}

AIC : 485.714 Q(6): 0.2066 (0.1505) Q (12) : 2.5698 (0.1089) Q (24) : 2.5474 (0.1104)

Normality Test Statistics of the standardized residuals 3.267 (0.1952)

Note: Numbers in parentheses and brackets are the $p$ values and confidence intervals at $95 \%$, respectively. $Q(i)$ reports Wooldridge (1991)'s robust LM test for $i$ th lag and $p$ values are reported next to test statistics in parentheses.

it is positive for eight periods and negative after it. However, only the positive part is statistically significant and this is for three periods only.

25 years, the period between 1984 and 2009, is long for a country such as Turkey. Factors such as structural reforms, globalization and changes in exchange-rate regimes can alter the inflation-inflation uncertainty relationship. Thus, we estimate the specification for two sub-samples: 1984-1993 and 1995-2009. We exclude 1994 to avoid the financial crises in that year. The estimates for the specification regarding the sub-periods are reported in Tables 2 and 3. The corresponding impulse responses are reported in Figs. 2 and 3. The signs of the estimated coefficients for the two sub-samples that we consider do not change compared to the full-sample estimates. It seems that inflation and inflation volatility become more persistent. The estimated coefficient 

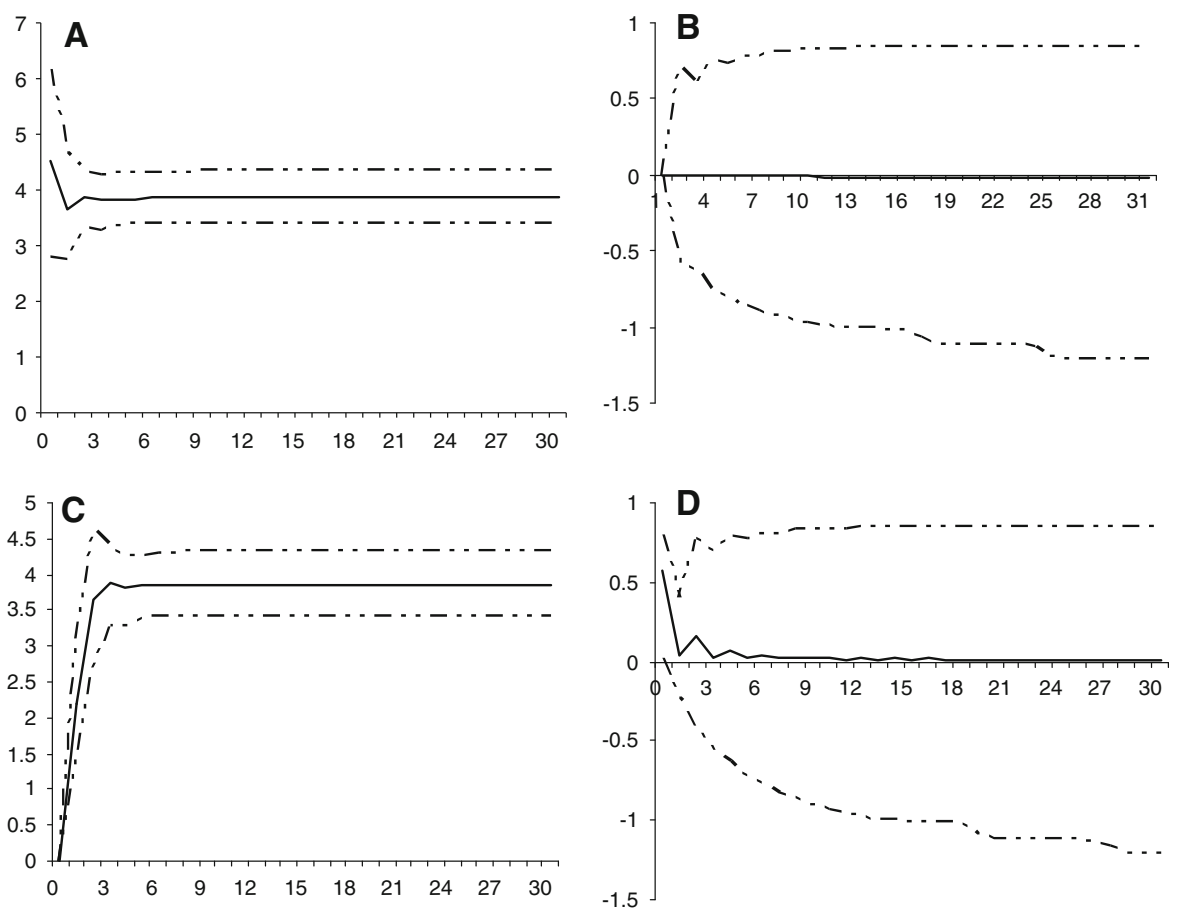

Fig. 2 The impulse responses of inflation and inflation volatility: 1984:01-1993:12. a Response of inflation to inflation, $\mathbf{b}$ Response of inflation volatility to inflation, $\mathbf{c}$ Response of inflation to inflation volatility, d Response of inflation volatility to inflation volatility

for the lagged inflation in the inflation volatility specification, $\delta_{1}$, becomes negative for the second sub-sample, but this coefficient is not statistically significant for either the full sample or for the two sub-samples. The response of inflation volatility to inflation is slightly positive for the first sample and negative for the second sample. However, these impulses are not statistically significant for the two sub-samples. For the responses of inflation to inflation volatility shocks the estimates are positive. The effects are positive and significant for 30 periods in the estimates from the first sub-sample but significant for only 15 periods in the second sub-sample. Overall, the estimated coefficients and impulse responses for the two sub-samples are qualitatively the same in the full-sample estimates. Thus, we claim that the estimates do not have any break points for the dates that we consider.

As elaborated above, ARCH-type models specify volatility as a predetermined function of lagged inflation innovations as well as the lagged value of volatility measures. Thus, it is not possible to define the stochastic element in volatility measures and assess its effect on inflation. Since ARCH and SV models are non-nested, they are not comparable with each other, however, various studies provide empirical evidence that SV models provide a better fit than ARCH models. Nevertheless, Kim et al. (1998) and Pederzoli (2006) compare their SVM specification with ARCH-type specifications by comparing their likelihood values (without calculating any statistical tests). 

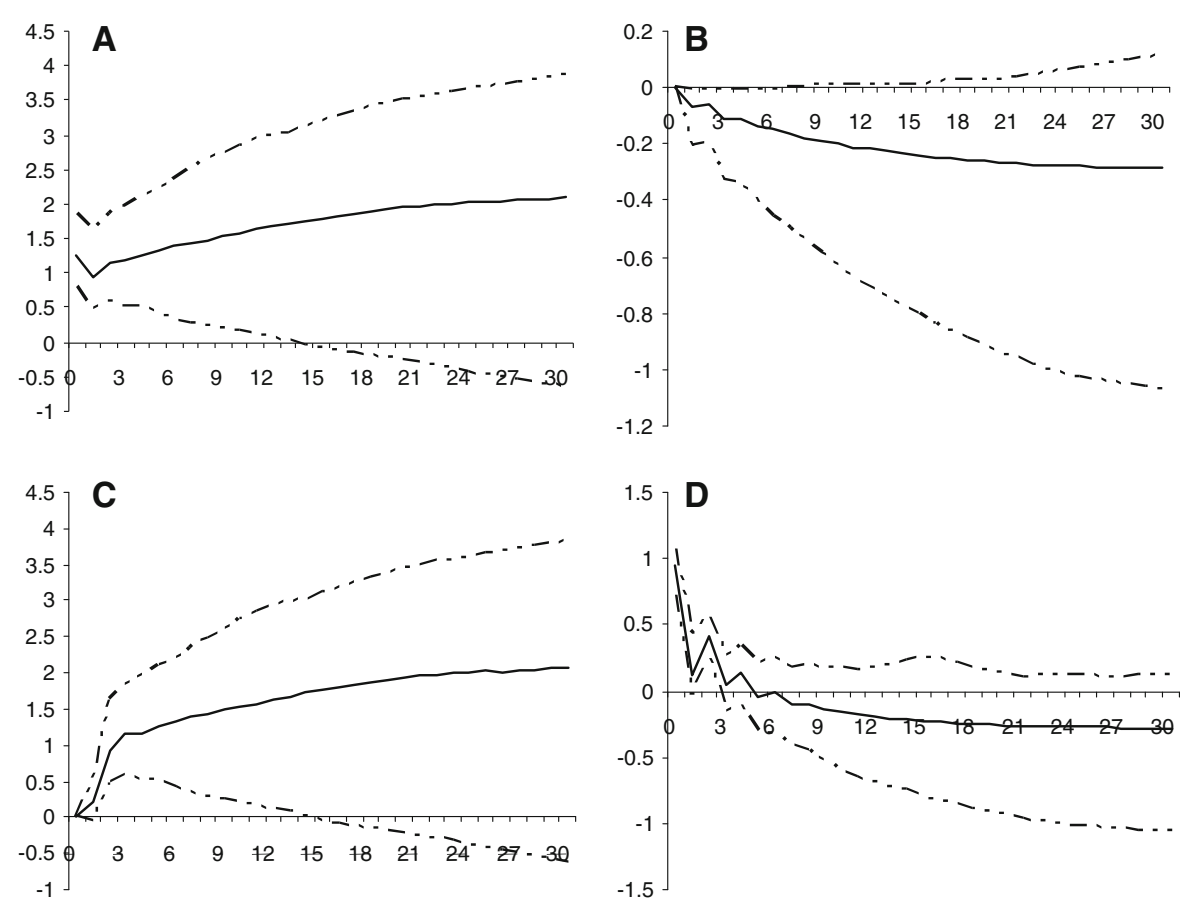

Fig. 3 The impulse responses of inflation and inflation volatility: 1995:01-2009:02. a Response of inflation to inflation, $\mathbf{b}$ Response of inflation volatility to inflation, $\mathbf{c}$ Response of inflation to inflation volatility, d Response of inflation volatility to inflation volatility

Similarly, as a tentative exercise, we estimate the EGARCH equivalent of our benchmark model (not reported here). The log likelihood value of the EGARCH equivalent model was -488.552 , whereas the log likelihood value of the SV model was -482.861 . Since the likelihood value is bigger (not in absolute value) for the SV specification, this could be taken as an indicator of superiority of the SV model compared to the ARCH-type model.

\section{Discussion}

Our results reveal that higher inflation uncertainty leads to higher inflation, not the other way around. Figure 4 plots monthly inflation and the SV measure, which also reveals that volatility precedes inflation. Cukierman and Meltzer (1986) reason this to be because higher uncertainty creates an incentive for policy makers to act opportunistically and create surprise inflation. This reasoning is in line with the Turkish political/bureaucratic structure. Note that the Central Bank of the Republic of Turkey (CBRT) is considered as having a low level of independence (Neyapti and Berument 1999). Thus, it is not likely that the CBRT is able to resist pressure from the government to create surprise inflation. Turkish inflation patterns closely coincide with Turkish political business cycles (Ergun 2000). Inflation usually increases during 


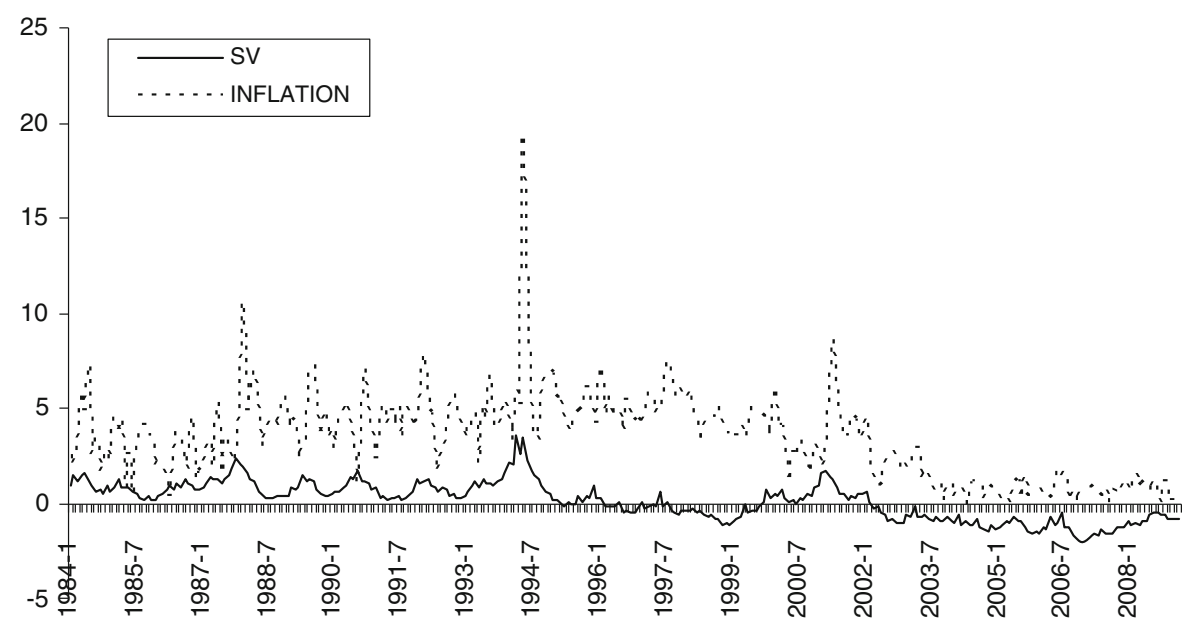

Fig. 4 Inflation and inflation volatility measures

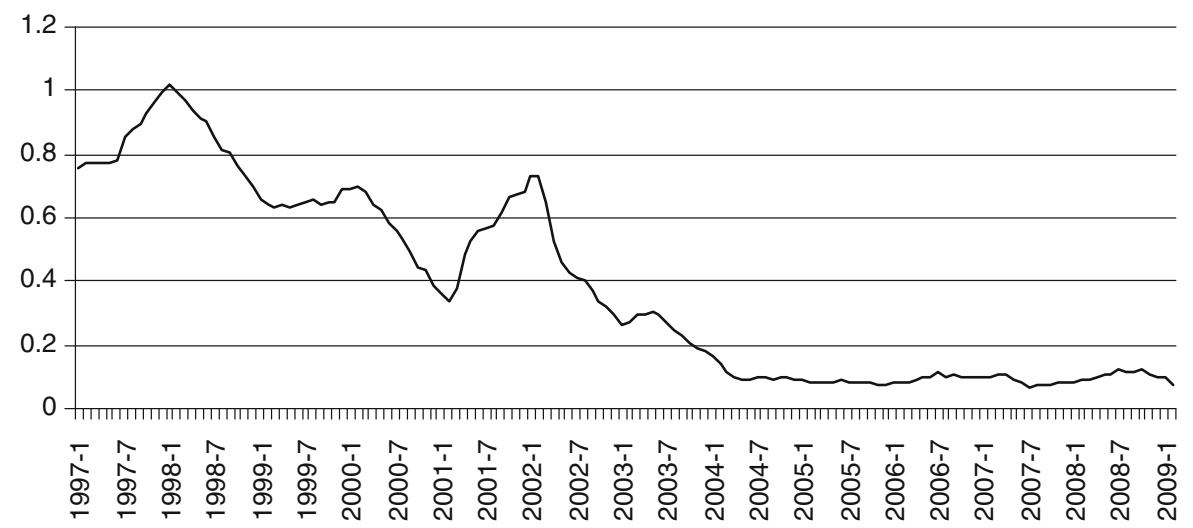

Fig. 5 Annual inflations compared to previous years' values

elections. Election timing may not be generally considered uncertain. However, Turkey did not have any general election, that is, no 'early election,' for the period that we consider. Thus, uncertain election timing coincides with low central bank independence to create an environment for inflation uncertainty that is likely to precede inflation. Thus, inflation uncertainty that leads to inflation is in line with Turkish economic structure.

Regarding the implication of our findings for policy making, one of the important costs of inflation concerns the uncertainty about future levels of inflation. Higher levels of uncertainty make it more difficult for consumers and firms to make their decisions. This negatively affects resource allocation and may lower output and employment. Our findings that inflation uncertainty precedes inflation suggest that adopting a gradualist disinflation program would be more effective at decreasing inflation uncertainty (and, therefore, at decreasing inflation) than 'cold-turkey', one-time, quick-fix disinflation programs because decreasing inflation uncertainty takes long and requires both short 
term policy and long-term structural reforms. ${ }^{8}$ In Turkey, these reforms might include granting higher levels of autonomy to the central bank to eliminate the government's role as market makers in such commodities as oil, electricity, wheat and hazelnuts.

The Turkish inflation experience supports our recommendation that gradualist policies rather than 'cold-turkey'-type policies are more successful at controlling inflation. In 2000, Turkey adopted an 'exchange-rate-based stabilization program': a quick-fix policy to lower inflation based on the crawling-peg exchange-rate regime. The goal of the policy was to decrease the level of inflation to $25 \%$ by the end of 2000 and to $12 \%$ by mid-2001. However, Turkey abandoned the program in February 2001 due to associated speculative currency attacks and annual value of the overnight interest rates reached to $5000 \%$. The realized inflation figures were 39 and $56 \%$ by the end of 2000 and June 2001, respectively. The latest effort to stabilize inflation is based on a gradualist program and seems to be more successful. Turkey launched its 18th standby program in February 2002 with the IMF. This program includes a set of structural reforms, including the social security system, tax policy and the banking sector. In January 2005, a month before the end of the program, its end date was extended to May 2008 with a 19th stand-by agreement. The target inflation rates were $8 \%$ in 2005 , $5 \%$ in 2006 and $4 \%$ in 2007 and the realization is 7.7, 9.6 and $8.3 \%$, respectively. Thus, we could consider that the program was moderately successful. Since the end of the agreement in May 2008, the credibility of government-announced targets has begun to be questioned and there is an upward trend in inflation. The target inflation was $4 \%$ in 2008 , which was realized by $10.06 \%$.

One may need to be cautious about the further implications of our model for policy selection recommendations: should a disinflation program be exchange-rate or moneyaggregates based and what kind of structural reforms are needed to accompany such a program? Our model is based upon a univariate setup; both inflation and inflation volatility measures are affected by each other. However, inflation and its volatility can be affected by other factors. Inflation can be affected by exchange rate, money supply and government deficit, and inflation volatility can be affected by a country's openness, exchange-rate regime or monetary-policy regime (such as inflation targeting versus exchange-rate targeting). One may need to incorporate the feedback effect of other determinants of inflation to inflation and/or changes in inflation volatility determinants to further elaborate on optimum policy selections for stabilizing inflation. These hypotheses are left for future study.

\section{Conclusion}

The positive relationship between inflation and inflation volatility is a wellestablished phenomenon. The direction of this relationship is crucial as the selection of a stabilization program to decrease inflation and the success of the program depends on this relationship. This article attempts to investigate the relationship between inflation and inflation volatility in a dynamic framework by using Turkish monthly data from

\footnotetext{
8 If higher inflation is the cause of higher inflation uncertainty, then 'cold-turkey'-types of disinflation programs could be adopted to lower inflation so that uncertainty will also be lower.
} 
1984 to 2009. In order to assess this relationship, we employ the stochastic volatility model framework; this allowed us to assess the effect of inflation volatility shocks on inflation over time. When we assess the interaction between inflation and its volatility, the empirical findings indicate that response of inflation to inflation volatility is positive and statistically significant. This supports the Cukierman and Meltzer (1986) proposition that higher inflation uncertainty leads to a rise in the optimal inflation rate.

Acknowledgements We would like to thank to The Turkish Scientific and Technological Research Council for their partial financial support (SOBAG-105K006).

\section{Appendix}

There are various statistical methods for modelling changing volatility. In these models, the mean equation can be defined as

$$
\pi_{t}=\mu_{t}+\sigma_{t} \varepsilon_{t}, \quad \mu_{t}=a+\sum_{i=1}^{k} b_{i} x_{i, t},
$$

where the disturbance term $\varepsilon_{t}$ is independently and identically normally distributed with zero mean and unit variance, $\mu_{t}$ is the conditional mean and depends on a constant term, $a$ and a set of explanatory variables, $x_{1, t}, x_{2, t}, \ldots x_{k, t}$. The lagged values of the dependent variable can also be included in the model as a part of the exogenous variable set. The mean adjusted series, therefore, can be defined as white noise with the unit variance multiplied by the volatility $\left(\sigma_{t}\right)$ process.

In order to capture the time-varying volatility, Autoregressive Conditional Heteroskedasticity (ARCH)-type models developed by Engle (1982) and Bollerslev (1986), and Stochastic Volatility (SV) models developed by Taylor $(1980,1982)$ are the most common. The variance equation for ARCH-type models defines the time-varying variance as a predetermined function of past squared innovations (Pederzoli 2006; Chen et al. 2008, p. 567.) For example, the variance specification for the ARCH(q) model can be written as

$$
\sigma_{t}^{2}=\alpha_{0}+\sum_{i=1}^{q} \alpha_{i} \varepsilon_{t-i}^{2}
$$

and for the Generalized Autoregressive Conditional Heteroskedasticity (GARCH) $(\mathrm{p}, \mathrm{q})$ model it can be written as

$$
\sigma_{t}^{2}=\alpha_{0}+\sum_{i=1}^{q} \alpha_{i} \varepsilon_{t-i}^{2}+\sum_{i=1}^{p} \beta_{i} \sigma_{t-i}^{2}
$$

where $\sigma_{t}^{2}$ captures the conditional variance of $\varepsilon_{t}$. As ARCH-type models are function of observed variables from the previous periods, they do not allow any noise in the volatility structure, and volatility is, therefore, a predetermined function of historical 
data. In the case of $\mathrm{ARCH}$ models, the volatility forecasting is straightforward since the one-step-ahead variance is fully predetermined. Contrary to ARCH models, SV models assume that the unknown volatility changes stochastically over time and contain an unobserved variance component (Pederzoli 2006). This feature of SV models can be regarded as an alternative to ARCH models, which have relied on simultaneous modelling of the first and second moments.

In the SV model, the variance equation is specified in logarithmic form, that is:

$$
\sigma_{t}^{2}=\sigma^{* 2} \exp \left(h_{t}\right)
$$

where $\sigma^{*}$ is a positive scaling factor. The stochastic process $h_{t}$ is modeled as a firstorder autoregressive model:

$$
h_{t}=\phi h_{t-1}+\sigma_{\eta} \eta_{t}, \quad \eta_{t} \sim N I D(0,1),
$$

where $h_{t}=\ln \left(\sigma_{t}^{2} / \sigma^{* 2}\right)$. The variance of the log-volatility process, $\sigma_{\eta}^{2}$, measures the uncertainty about future volatility. If $\sigma_{\eta}^{2}=0$, then the first-order SV model is not identified. $\phi$ is often considered as a measure of the persistence of shocks to the volatility; when $\phi$ is close to 1 and $\sigma_{\eta}^{2}$ is close to 0 , the evolution of volatility over time is very smooth. If $|\phi|=1$ and $\sigma_{t}^{2}=0$, the volatility is constant over time. If $|\phi|<1$, then $\sigma_{t}^{2}$ and $y_{t}$ are considered stationary processes (Broto and Ruiz 2004). Therefore, $\phi$ is restricted to less than one in an absolute value. It is assumed that the disturbances $\varepsilon_{t}$ and $\eta_{t}$ are mutually uncorrelated contemporaneously and at all lags. Equations (a.1) and (a.3) represent the SV model. Alternative specifications for the $\mathrm{SV}$ specification can be written as

$$
\begin{aligned}
\ln \sigma_{t}^{2} & =\ln \sigma^{* 2}+h_{t} \\
& =\ln \sigma^{* 2}+\phi\left(\ln \sigma_{t-1}^{2}-\ln \sigma^{* 2}\right)+\sigma_{\eta} \eta_{t} \\
& =(1-\phi) \ln \sigma^{* 2}+\phi \ln \sigma_{t-1}^{2}+\sigma_{\eta} \eta_{t} .
\end{aligned}
$$

Since the term $\ln \sigma^{* 2}$ can be regarded as the constant term in the logarithm of the volatility equation $h_{t}$, the logarithm of the volatility process does not include an additional intercept term. Koopman and Uspensky (2002) include an additional explanatory variable - the variance process itself - in the mean equation and estimate the coefficients simultaneously with the parameters of the volatility process. The new model is called the SV-in-Mean (SVM) model, where the mean equation and variance equation are written as 9

$$
\pi_{t}=a+\sum_{i=1}^{k} b_{i} x_{i, t}+d \sigma^{* 2} \exp \left(h_{t}\right)+\sigma^{*} \exp \left(0.5 h_{t}\right) \varepsilon_{t}, \quad \varepsilon_{t} \sim \operatorname{NID}(0,1)
$$

$$
h_{t}=\phi h_{t-1}+\sigma_{\eta} \eta_{t}, \quad \eta_{t} \sim N I D(0,1)
$$

9 The estimated model in this study has two lags. 
where the disturbances $\varepsilon_{t}$ and $\eta_{t}$ are assumed mutually uncorrelated contemporaneously and at all lags. $d$ is a risk premium coefficient to capture the volatility-in-mean effect. The main difference compared to ARCH-type models is that in the SV model the predictive density, $f\left(\pi_{t} \mid \Omega_{t-1}\right)$, cannot be expressed in closed form, and so $\pi_{t} \mid \Omega_{t-1}$ does not have an analytic expression where $\Omega_{t-1}$ denotes the available information set at time $t-1$. Therefore, the SV model's likelihood function is intractable and cannot be easily computed (Pederzoli 2006; Krichene 2003). The main drawback with SV models has been the problem of obtaining parameter estimates using the maximum likelihood since it is difficult to evaluate the likelihood function. A variety of estimation procedures has been proposed for the SV models, such as the Generalized Method of Moments (Melino and Turnbull 1990), the Quasi Maximum Likelihood (Harvey et al. 1994; Ruiz 1994), the Efficient Method of Moments (Gallant et al. 1997), the Markov-Chain Monte Carlo approach (Jacquier et al. 1994; Andersen et al. 1999; Kim et al. 1998). In this article, the parameters of the SVM model are estimated by exact maximum likelihood methods using Monte Carlo importance sampling techniques. This method has some distinct advantages: First, as it integrates the Kalman Filter and simulation smoother into the analysis of non-Gaussian models, it exploits the structure of the specification to improve the speed of the convergence. Second, it approximates only log likelihood, so as the dimension of state is increased the computational efficiency of the method should not diminish significantly. Last, it can be extended to a multivariate case by using the multivariate Taylor series expansion of log likelihood function (Shephard and Pitt 1997, for details). Therefore, by using this method explanatory variables can be included in the mean equation and their coefficients can be estimated simultaneously with the parameters of the volatility process.

Parameters of the SVM model are estimated by the simulated maximum likelihood method. Let the unknown parameters vector be $\psi=\left(\phi, \sigma_{\eta}, \sigma^{* 2}, d\right)^{\prime}$. Since the variance of disturbance term in $y_{t}$ is given by $\sigma^{* 2} \exp \left(h_{t}\right)$, which is a stochastic, the SVM model is nonlinear. Moreover, since both mean and variance equations have a latent variable $h_{t}$, the construction likelihood for the SVM model is complicated. Koopman and Uspensky (2002) adopt the Monte Carlo likelihood approach developed by Shephard and Pitt (1997) and Durbin and Koopman (1997). This simulation method of computing the likelihood function can be derived as

$$
L(\psi)=p(\pi / \psi)=\int p(\pi, \theta / \psi) d \theta=\int p(\pi) p(\theta / \psi) d \theta,
$$

where $\psi=\left(\phi, \sigma_{\eta}, \sigma^{* 2}, d\right)^{\prime}, \theta=\left(h_{1}, \ldots, h_{T}\right)^{\prime}$. An efficient way of evaluating such expressions is by using importance sampling (Ripley 1987); let $\hat{p}(\pi / \theta, \psi)$ be an arbitrary conditional density, which is positive $(>0)$ everywhere, of given $\pi$ and $\psi$. In order to achieve efficiency, $\hat{p}(\pi / \theta, \psi)$ is chosen to be as close as possible to $p(\pi / \theta, \psi)$. The choice for the importance density is the conditional Gaussian density since in this case it is relatively straightforward to sample from $\hat{p}(\pi / \theta, \psi)=g(\pi / \theta, \psi)$. The simulation smoother of De Jong and Shepard (1995) can be used to sample from the approximating Gaussian model $g(\pi / \theta, \psi)$. The likelihood function of the approximating Gaussian model can be calculated via the Kalman Filter. Guidelines for the 
construction of an importance model and the likelihood function for the SV model are given by Hol and Koopman (2000), Durbin and Koopman (2002) and Asaf (2006). ${ }^{10}$

\section{References}

Andersen T, Chung H, Sorensen BE (1999) Efficient method of moments estimation of a stochastic volatility model: a Monte Carlo study. J Econ 91:61-87

Asaf A (2006) The stochastic volatility in mean model and automation: evidence from TSE. The Quart Rev Econ Financ 46:241-253

Ball L (1992) Why does high inflation raise inflation uncertainty? J Monet Econ 29:371-388

Berument H, Dincer NN (2005) Inflation and inflation uncertainty in the G-7 countries. Physica A 348:371379

Berument H, Metin-Ozcan K, Neyapti B (2001) Modelling inflation uncertainty using EGARCH: an application to Turkey. http://www.econturk.org/Turkisheconomy/kivil2.pdf

Berument H, Kilinc Z, Ozlale U (2005) The missing link between inflation uncertainty and interest rates. Scottish J Political Econ 52: 2-241

Bollerslev T (1986) Generalized autoregressive conditional heteroskedasticity. J Econ 31:307-327

Broto C, Ruiz E (2004) Estimation methods for stochastic volatility models: a survey. J Econ Surveys 18:5

Brunner AD, Hess G (1993) Are higher levels of inflation less predictable? A state-dependent conditional heteroskedasticity approach. J Bus Econ Stat 11:187-197

Chen CWS, Gerlach R, So MKP (2008) Bayesian model selection for heteroskedastic models. In: Chib S, Griffiths B, Koop G, Terrell D (eds) Bayesian econometric methods. Advances in econometrics. Elsevier Science, Amsterdam, pp 567-594

Cukierman A (1992) Central bank strategy, credibility and independence: theory and evidence. MIT Press, Cambridge

Cukierman A, Meltzer A (1986) A theory of ambiguity credibility and inflation under discretion and asymmetric information. Econometrica 54:1099-1128

Danielsson J (1994) Stochastic volatility in asset prices, estimation with simulated maximum likelihood. J Econ 64:375-400

De Jong P, Shepard N (1995) The simulation smoother for time series models. Biometrika 82:339-350

Doornik J (1998) Object-oriented matrix programming using Ox 2.0. London: Timberlake Consultants Ltd. http://www.nuff.ox.ac.uk/Users/Doornik

Durbin J, Koopman SJ (1997) Monte carlo maximum likelihood for non-gaussian state space models. Biometrika 84:669-684

Durbin J, Koopman SJ (2002) A simple and efficient simulation smoother for state space time series analysis. Biometrika 3:603-616

Elder J (2004) Another perspective on the effects of inflation uncertainty. J Money Credit Banking 36(5):911-928

Engle R (1982) Autoregressive conditional heteroscedasticity with estimates of the variance of U.K. inflation. Econometrica 50:987-1008

Ergun M (2000) Electoral political business cycles in emerging markets: evidence from Turkey Russian and East European. Financ Trade 36(6):6-32

Evans M (1991) Discovering the link between inflation rates and inflation uncertainty. J Money Credit Banking 23:169-184

Franses PhH, van der Leij MJ, Paap R (2008) A simple test for GARCH against a stochastic volatility model. J Financ Econ 6(3):291-306

Friedman M (1977) Nobel lecture: inflation and unemployment. J Political Econ 85:451-472

Gallant AR, Hsieh DA, Tauchen GE (1997) Estimation of stochastic volatility models with diagnostics. J Econ 81:159-192

Grier K, Perry MJ (1998) On inflation and inflation uncertainty in the G7 countries. J Int Money Financ 17:671-689

Grier K, Perry MJ (2000) The effects of real and nominal uncertainty on inflation and output growth: some GARCH-M evidence. J Appl Econ 15(1):445-458

$\overline{10}$ Please see Koopman and Uspensky (2002) for further information concerning SVM models. 
Harvey AC, Ruiz E, Shephard N (1994) Multivariate stochastic variance models. Rev Econ Stud 61:247264

Hamilton JD (1994) Time series analysis. Princeton University Press, Princeton

Hol E, Koopman SJ (2000) Forecasting the variability of stock index returns with stochastic volatility models and implied volatility. http://www.timbergen.nl

Holland S (1993) Comment on inflation regimes and the sources of inflation uncertainty. J Money Credit Banking 25:514-520

Holland S (1995) Inflation and uncertainty: tests for temporal ordering. J Money Credit Banking 27: $827-837$

Jacquier E, Polson NG, Rossi PE (1994) Bayesian analysis of stochastic volatility models (with discussion). J Bus Econ Stat 12:371-389

Kim S, Shephard N, Chib S (1998) Stochastic volatility: likelihood inference and comparison with ARCH models. Rev Econ Stud 65:361-394

Klein B (1978) The measurement on long and short-term price uncertainty: a moving regression time series analysis. Econ Inq 16:438-452

Koop G, Pesaran MH, Potter SM (1996) Impulse response analysis in nonlinear multivariate models. J Econ 74(1):119-147

Koopman SJ, Uspensky EH (2002) The stochastic volatility in mean model: empirical evidence from international stock markets. J Appl Econ 17:667-689

Koopman SJ, Shephard N, Doornik JA (1999) Statistical algorithms for models in state space form using SsfPack 22. Econ J 2:113-166

Krichene N (2003) Modeling stochastic volatility with application to stock returns IMF Working Papers, No 03/125. http://www.imf.org/e.../wp/2003/wp03125.pdf

Melino A, Turnbull SM (1990) Pricing foreign currency options with stochastic volatility. J Econ 45: 239-265

Nas TF, Perry MJ (2000) Inflation, inflation uncertainty, and monetary policy in Turkey: 1960-1998. Contemp Econ Policy 18(2):170-180

Neyapti B (2000) Inflation and inflation uncertainty in Turkey: evidence from the past two decade. http:// www.bilkent.edu.tr/ neyapti/shortstudies/012000.pdf

Neyapti B, Berument H (1999) Turkiye Cumhuriyet Merkez Bankasi ne kadar bagimsiz?. Iktisat Isletme ve Finans 14(165):11-17

Ozer M, Turkyilmaz SA (2005) Time series analysis of inflation and inflation variability in Turkey. J Econ Manag Financ 20:229

Pederzoli C (2006) Stochastic volatility and GARCH: a comparison based on UK stock data. Eur J Financ 12(1):41-59

Ripley B (1987) Stochastic simulation. Wiley, New York

Ruiz E (1994) Quasi-maximum likelihood estimation of stochastic volatility models. J Econ 63:289-306

Shephard N, Pitt M (1997) Likelihood analysis of non-gaussian measurement time series. Biometrika 84:653-667

Taylor SJ (1980) Conjectured models for trend in financial prices, tests and forecasts. J Royal Stat Soc 143(A):338-362

Taylor SJ (1982) Financial returns modelled by the product of two stochastic processes — a study of daily sugar prices. In: Anderson OD SJ (ed) Time series analysis: theory and practice 1. North-Holland, Amsterdam, pp 203-226

Telatar F, Telatar E (2003) The relationship between inflation and different sources of inflation uncertainty in Turkey. Appl Econ Lett 10:431-435

van Dijk D, Franses PH, Boswijk HP (2007) Absorption of shocks in nonlinear autoregressive models. Comput Stat Data Anal 51:4206-4226

Wooldridge JM (1991) On the applications of robust, regression-based diagnostics to models of conditional means and conditional variances. J Econ 47:5-46

Yao Q, Tong H (1994) Quantifying the influence of initial values on non-linear prediction. J Royal Stat Soc 56(B):701-725 